\title{
Editorial
}

\section{Light alloys for transport: the value of time and hard work for age hardening of light alloys, from Alfred Wilm to present days}

\section{O. Hardouin Duparc}

LSI, CNRS-CEA-X, École Polytechnique, 91128 Palaiseau Cedex, France e-mail: olivier.hardouinduparc@polytechnique.edu

e are happy to present to the Readers of the Revue de Métallurgie (International Journal of Metallurgy - From Making to Using) a special ensemble of four papers dedicated to Light Alloys for Transportation.

These papers have been written after the 6th 3M colloquium "Materials, Mechanical properties, Microstructure" which was held June 20-21, 2011, at the Institut National des Sciences et Techniques Nucléaires, Saclay. The theme was: "Light Alloys for Transportation." $3 \mathrm{M}$ colloquia are organised each year by Professors in charge of the MSE (Materials for Structures and Energy) Master of Science program: V. Aubin and P. Bompard (Centrale Paris), Y. Bienvenu (Mines ParisTech), I. Guillot (Université Paris-Est Créteil Val de Marne), M. Gupta (Université Paris-Sud 11), O. Hardouin Duparc (École Polytechnique ParisTech), P. Marcus (Chimie ParisTech) and C. Meis (INSTN, CEA). The colloquium topic is different every year and is connected to a bibliographical project proposed to Master's students. The aim is to gather academics with an expertise in chemistry, physics or mechanical behaviour of materials with people from the industrial world and, of course, the Master's student themselves.

At the beginning of the last century, the scientist-engineer Alfred Wilm working near Berlin, at a place where the Babelsberg Film Studio is now to be found, discovered a way to significantly improve the mechanical properties of an aluminium alloy thanks to a particular Time-Temperature treatment. This took him several years of trials and slow progress from 1903 to 1909 with several patents, even if none of them proved useful to protect his rights on the invention. Experience in the metallurgy of steels as well as tenacity and hard work were certainly more necessary to this achievement than mere chance despite what romantic popularization of Science tries to make us believe (as with Newton's apple or Haüy's happy awkwardness) even if Wilm himself contributed to this movie-like scenario towards the end of his life in 1936, in plain contradiction to what he wrote in 1913 (see [1,2]. The Universal Film studios had already shot many films in Babelsberg, including von Sternberg's The Blue Angel). Although not hard enough for the Prussian military authorities which had ordered the research work, Duralumin $(<$ Hartaluminium) and its likes allowed for the formidable development of air transport, airships and airplanes, in France and in Germany first (after a failed attempt in Great Britain as soon as in 1909), then in the US and worldwide. Air transport as well as terrestrial transport: cars and also, and especially, bicycles (gas once was cheaper than muscular effort). Alfred Wilm published in the German journal Metallurgie in 1911 and Henry Le Chatelier and Léon Guillet had his paper immediately summarized in French in the Revue de Métallurgie [3]. On the theoretical side, Paul Merica 
carried out between 1914 and 1919 in the US the research work Léon Guillet, whose 1902 PhD thesis was about aluminium alloys, was prevented from doing in France because he was given as a priority to "Taylorize" the hardening of steel shells. This analysis of aluminium based binary phase diagrams allowed to predict which alloys can harden according to the Wilm's procedure. The British chemical metallurgist Cecil Desch explained in 1934 where the quenched copper atoms should gather in the aluminium lattice, viz. as small groups in $\{100\}$ crystallographic planes. These zones came to be detected in the reciprocal space through X-ray diffuse scattering by George Preston near London and by André Guinier in Paris [4]. Experimental techniques have considerably evolved since those days, towards straight real space visualization with high resolution electron microscopes. The understanding and mastering of the microstructural alloying processes as well as of the hardening mechanisms for aluminium and magnesium based light alloys is also still improving, allowing for better efficiency and energy savings in transports. It also implies a good understanding of mechanical fatigue as well as of chemical corrosion which are temperature and environment dependent. The Metal Highlights section of the Revue regularly mentions headways in this field in the industrial world, as with the Constellium Airware ${ }^{\mathrm{TM}}$ technology for instance. In parallel with research in carbon fiber composite materials, titanium or nickel based alloys and also hightech steels, research in aluminium or magnesium based alloys is still active in order to save metal and energy demands for a more sustainable world. Let us finally mention another kind of mainly aluminium-based alloys which has received the fame of a Nobel Prize that very same 2011 year, namely the Quasicrystals. Although these alloys have not yet found large scale industrial applications in transport, they do transport crystallographer theoreticians' thoughts, but this is another story.

The following papers are research articles whose Authors and Referees we heartfully thank.

\section{References}

[1] O. Hardouin Duparc, Revue de Métallurgie 5 (2004) 353-360

[2] O. Hardouin Duparc, Int. J. Mater. Res. 96 (2005) 398-404

[3] Recherches physicométallurgiques sur les alliages d'aluminium et de magnésium, Revue de Métallurgie 8 (1911) 831-833

[4] O. Hardouin Duparc, Metallurgical and Materials Transactions A 41 (2010) 1873-1882 